\title{
Fishery research: current approaches, tensions and emerging aspects. The future and how to approach it
}

\author{
CARLES BAS \\ Institut de Ciències del Mar (CSIC), Passeig Marítim de la Barceloneta 37-49, \\ 08003 Barcelona, Spain.
}

\begin{abstract}
SUMMARY: The current development of fishery research can be considered as much a technical development as a scientific-conceptual one. In relation to the technical development we analyse the evolution of the concepts fishing effort and fishing power, as well as vulnerability, availability and accessibility. In the conceptual analysis of the basic parameters we consider new contributions with regards to recruitment and evolution of populations based on concepts such as the system's carrying capacity and the effect of inverse density dependence. The impact of the available space is analysed as well as the effect of the prey-predator relationship in the context of the flows between the different levels in the trophic web. We point out that fishery analysis strategies need to consider that, from both the biological and socio-economic points of view, the system is never balanced but rather is at the very limit or even over the limit. On the whole, fishing (human action on the resource) can be understood within the context of the ecosystem. This situation implies introducing the concept of uncertainty. Aspects such as ecosystem elasticity are analysed in their broadest sense. In these terms, recovery of an ecosystem and of Large Marine Ecosystems (LME) is still possible, but the result can be different due to the appearance of opportunistic species. Some concepts such as fuzzy sets, and chaos and fractal analysis are important tools for analysing the evolution and management of ecosystems exploited by fisheries.
\end{abstract}

Keywords: fishing, recruitment, fishing power, vulnerability, carrying capacity, inverse density dependence, elasticity, uncertainty, Large Marine Ecosystems (LME).

RESUMEN: INVESTIGACIÓN PESQUERA: PERSPECTIVA ACTUAL, TENSIONES Y ASPECTOS EMERGENTES. EL FUTURO Y SU APROXIMACIÓN. - El desarrollo actual de la ciencia de las pesquerías es considerado tanto como desarrollo técnico como desarrollo científico-conceptual. En el primer aspecto se analiza la evolución de los conceptos: esfuerzo de pesca y poder de pesca. Así como la vulnerabilidad disponibilidad y accesibilidad. Se considera el análisis conceptual de los parámetros básicos con nuevas aportaciones sobre el reclutamiento y la evolución de las poblaciones a partir de conceptos como la capacidad de carga del sistema y el efecto de la densodependencia inversa. Se analiza el impacto del espacio disponible así como el efecto de la relación presa-depredador en el contexto de los flujos entre los diversos niveles de la relación trófica. La estrategia se sitúa considerando que tanto desde el punto de vista biológico como socieconómico el sistema no está nunca en equilibrio sino en el límite o fuera del mismo. En conjunto la pesca -acción del hombre sobre el recurso- se sitúa en el contexto del ecosistema. Esta situación implica introducir situaciones de incertidumbre. Se analizan aspectos como la elasticidad de los ecosistemas en su aspecto amplio. En estos términos la recomposición de un ecosistema y también de Large Marine Ecosystems (LME) es posible, pero el resultado puede ser diferente -aparición de especies oportunistas. Algunos conceptos como los conjuntos borrosos, el análisis caótico y la fractalidad son instrumentos importantes en el análisis de la evolución y el control de los ecosistemas depredados por la pesca.

Palabras clave: pesca, reclutamiento, poder de pesca, vulnerabilidad, capacidad de carga, densodependencia inversa, elasticidad, incertidumbre, Large Marine Ecosystems (LME). 


\section{INTRODUCTION}

Throughout history humans have endeavoured to learn about the marine environment but interest in the impact that humans have on this environment, i.e. fishing activity, is a relatively new concern. It began at the end of the $19^{\text {th }}$ century (Petersen, 1892). During the first half of the $20^{\text {th }}$ century the studies were usually biological in character and there were few quantitative studies. It was towards the second half of the $20^{\text {th }}$ century that two new focuses emerged: firstly, the specific human factor (human impact), and secondly, there were attempts to model the process (Schaefer, 1957; Ricker, 1954; Beverton and Holt,1956; Russell, 1931; Graham, 1935). If we take for granted that the concepts and the interactions of the parameters are sufficiently understood, there are two characteristics of the system modelling process that, as time goes on, need to be considered seriously: one is that parameters that are not constant need to be considered as such, and the other is the excessively schematic nature of the interrelations. In this context it is only possible to talk of biological-fishery research even though the main interest is the bio-ecological impact. Human impact has not been analysed in depth. It has only been recently that analyses have begun to consider that the economy and even more importantly the socioeconomy are based on human activity (Gordon, 1953; Crutchfield, 1979; Franquesa, 1996). But still in this context, socio-economic analyses seem to follow different reasoning from bio-ecologic analyses. Only very recently have there been attempts to relate and converge both lines of research. However, the true aim of the research is to model the processes of human activity (socio-economic) in relation to the resources (bio-ecologic). This model would fulfil two basic objectives: firstly it would take into account the fishing process in all its complexity, which justifies the existences of a fisheries science, and secondly it would assure the right conditions for adequate management and the possible consequences of applying appropriate regulations aimed at sustaining the fishing process as a whole.

However it is important to point out that in the 1920s two influential researchers had already formulated the prey-predator interrelationships in a simple and appropriate way. Although in their equation Lotka (1925) and Volterra (1926) related the predator with the prey in exclusively biological terms, it is possible to consider the resources as the prey and the fisher as the predator as long as we take into account that this predator follows socio-economic norms and not only bio-ecologic laws.

In this work we develop and reflect on this idea.

\section{Technical aspects of fishing}

It is very important to consider the following idea: humans have an impact on the marine resources through various technical processes. As pointed out above, at first this idea was barely considered although it quickly became understood as a key element. In this sense, the technological development applied to fishing has evolved rapidly and as a consequence human impact continually increases. It is imperative to understand and analyse this evolution in order to understand the fishing process.

The technological aspects of fishing need not be analysed by experts specialising in the bio-ecology of the exploited resources. The extremely rapid development of fishing technology makes it imperative that there is adequate parameterisation. There are two aspects that should be analysed: fishing power and fishing effort. Both concepts are difficult to define exactly, and as a consequence they are difficult to assess. It is generally forgotten that in both cases they are nothing more than the means humans (the fisher) use in their contact with the resources (extraction/fishing), and for this the strictly human aspect is very important for management; the fisher's preparation, experience, ability, etc. will have a decisive influence on effectively assessing these parameters, in particular for the fishing effort. In this aspect the adequate technological preparation of the fishing gear and boat must be taken into account.

\section{Fishing power}

Interpreting the values attributed to fishing power is very uncertain and using a base for comparison with a standard reference is very complicated. Using the trawler engine power is an aspect currently taken into account, but evidence shows that the correlation between power and fishing efficiency can be deceiving. Neither by using the power, the Gros Register Tons (GRT), nor the boat length (occasionally accepted as a reference), can a value or index be obtained that reliably reflects the fishing power as a useful parameter for estimating the fishers' capacity to act on the exploitable resource.

Any change in the structure or configuration of the boat equipment influences its capacity to act on the resource. As an example, the introduction of sonar 
implies a significant increase in the fishing power, which is difficult to quantify. If we examine the boats that fish with purse seine nets using a light to attract/concentrate the fish, there are also significant problems; the power and position of the spotlights are other factors that decisively modify the fishing power. In spite of the difficulties when small boats are used for purse seine fishing the usual practise is to use the light intensity as a reference of fishing power.

The fishing power doesn't only depend on the boat's characteristics, although it is the aspect used most, but also on the characteristics of the fishing gear used. This is especially significant in artisanal fishing in which the characteristics of the gear or equipment are without doubt the most important references. It is evident that the large drift net or long line gears require bigger boats but it is doubtful that the fishing power, although generally used, depends basically on the characteristics of the boat.

It is already complicated to introduce all these variables into the concept of fishing power, but it now becomes even more complicated when another very important factor is introduced: the human factor. A fishing crew that are technically prepared is a very positive factor in relation to fishing power, shown by the importance placed on selecting the crew of a fishing boat with the hope of improving the catch. It is therefore clear that it is an important component of fishing power. It is also evident that this aspect should also be considered as a component of the fishing effort although it will always be an updated version of what has been considered as the fishing power.

Most classic studies of fishing power continue to refer to a standard and it is possible to establish a regression which can be compared to the catch or the CPUE (Cash Per Unit Effort) with respect to the fishing power $F$ represented by the boat characteristics, either GRT or HP, all of which is elevated to a power $b\left(\mathrm{C}=\mathrm{F}^{\mathrm{b}}\right)$ (Lleonart, 1982) and therefore the fishing capacity of the boat $i$ with respect to the standard $k$ will be:

$$
\frac{H P_{i}}{H P_{k}}=b
$$

\section{Fishing effort}

We could define fishing effort as the fishing power in action, acting. This introduces the parameter of time into the concept. Therefore, the fishing effort is the fishing power in the time that it is acting.
It seems easy to measure time but there are actually many difficulties. We are really referring to the time of effective fishing, but straight away different problems arise. Without doubt the most important problem is the treatment that the searching time deserves, either searching for the fishing location or the shoal of fish. There are some in-depth studies on catching pelagic fish, in which it is very difficult to separate the fishing time, limited to catching the fish and the time involved in finding the school of fish. For the net, hook and fish-trap gears time is difficult to measure, more time does not necessarily imply a larger catch or even more possibilities. In these method there is what we could call a saturation level, which is arrived at before the largest possible catch (all the hooks have a fish, the mesh is completely full) is obtained, and in any case it is difficult to measure. Once the saturation level is reached, the rest of the time used is totally unproductive. It is therefore questionable if measuring real time and as a consequence measuring the effort is effective. This leads to the conclusion that time is an inadequate parameter and it is better to use the fishing power as the reference parameter when estimating fishing activity especially in relation to the last fishing gears mentioned.

An aspect that fits in with this scheme is related to the selectivity of the gear. Occasionally this factor is taken into account in the fishing power. It is evident that the selectivity of the gear that selects a particular species or certain size/age has a relationship with the fishing power, especially inasmuch as this activity relates not only to the exploited stock but also to the exploited ecosystem (Bethke, 2004). The traditional situation is related to the mesh or hook size. However, there are now other important aspects: the use of sorting grids and square-mesh panels (Sardá et al., 2004). Both systems imply a substantial change in the fishing power, fishing gear and overall fishing strategy. The implications are especially evident when we analyse the impact on the other components of the ecosystem in which the exploited stock lives, taking into account that it is impossible to separate the stock from the ecosystem. However there are very few studies that include selectivity in the concepts of fishing power and effort.

\section{Correlation between the effort and the catch}

In the Equation 1 that relates the catch and the fishing effort the value of the function known as $q$ is generally considered to be a constant value. The 
value $q$ has different forms, i.e. catchability, availability and accessibility, depending on the different aspects of this relationship, which in some cases affect the performance of the gear and in others the availability and behaviour of the exploited species. Moreover, in relation to the value $\mathrm{q}$ it is important to consider that the demographic structure of the catches reflects the population demographic structure and in this context $q$ can be defined as the probability that a unit of biomass is caught by a unit of fishing effort. This value has special significance when there is a uniform space and the effort distribution is aleatory. These circumstances, which are accepted in most studies, rarely occur in reality. However, it is not so much the characteristics of $\mathrm{q}$ that are important but its behaviour. Most authors tend to consider q as constant, but the reality is different: in daily experience we can observe numerous situations that show the changes in this "constant". It is normal that after a period of prohibition catches are unusually high; this situation corresponds to behaviour of more "availability" due to the species' trust, a question of etiological behaviour that disappears quickly, causing significant changes in the q value. Variations in food concentrations result in certain species accumulating in an area, for example the prized "Namibian hake", which varies in "catchability" depending on whether the fishers can find these masses that appear sporadically according to time and place. In other cases the accessibility of a species varies temporarily with respect to the fishing systems. In the case of squid, their movements related with the deeper or shallower depth of the school seem to vary their "accessibility" in relation to trawl gear, which is used a lot to catch them in some areas (Sahara). The result is always a change in the q value, which therefore loses its constant character. It is evident that these variations that are always important but generally difficult to quantify can be removed by taking an overall view of sufficiently long periods of time. Therefore, mean values and estimates are always used in fishery studies, which negatively affects the accuracy of the information. This is especially important when the progressive shortage of fishing resources requires better information to make more accurate estimates and controls of the fishing action. In addition, new technology allows fishers to act more efficiently on the stocks. Although it can be considered that this aspect is reflected in a higher fishing power, in fact it does so through an increase in the catchability that makes $q$ vary proportionally to the technological increase. The widespread use of net haulers for purse seine nets and other similar mechanisms for several types of equipment and gear (long lines, tremail nets, fixed nets) is translated into an increase in the catch capacity, catchability of the gear. All these cases and many others show us the ways in which the so-called constant q can vary.

\section{Some focuses related with bio-ecological aspects}

\section{Recruitment models}

The classic models accept that there is no relationship between the spawning stock and recruitment. Among others, Ricker and Beverton-Holt, have analysed the relationship and their formulations are widely accepted. Beverton-Holt introduces mortality indexes M1 and M2 in the period of prerecruitment, which are related to mortalities due to intrinsic and extrinsic causes, respectively. Other estimates, for example that of Shepherd (1982):

$$
R=\frac{\alpha S}{1+\left(\frac{S}{K}\right)^{\delta}}
$$

( $\mathrm{K}=$ carrying capacity, $\alpha=$ slope in origin and $\delta=$ compensation degree) that combines the expression formulated by Ricker and Beverton-Holt. Myers et al. (1995), modify their formulation to allow for the depensatory dynamic. The expressions proposed by Solari et al. (1997), and Bas et al. (1999), present a non-linear additive approach (Fig. 1.):

$$
R \approx \sum_{i=1}^{m} \frac{a(S)}{(S-b)^{2+c}}
$$

that not only allows various chaotic equilibriums that are limited by the carrying capacity variable, but also when this level is reached it can oscillate to another equilibrium cycle. This equation allows a chaotic density dependence governed by an attractor and an external density dependence related to the changes in the carrying capacity, also including the inverse density dependence that implies a certain low-level of spawners that doesn't insure recruitment as a consequence of the Allee effect (Allee et al., 1949), among other possibilities.

The proposed equation has varies advantages. In the first place it describes each chaotic cycle through the corresponding attractor and it is limited in each case by the corresponding carrying capacity. It allows the carrying capacity to vary and as a consequence various consecutive cycles result that take 


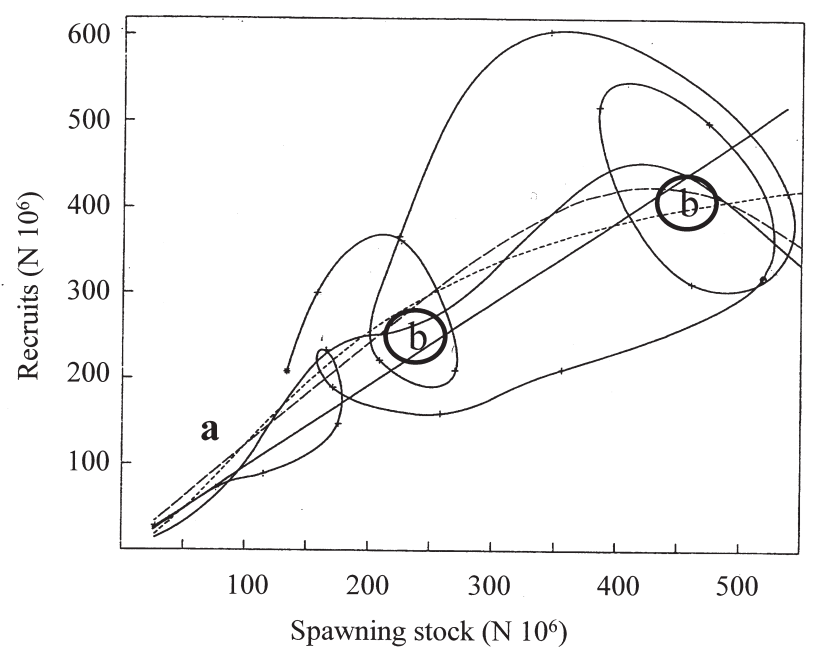

FIG. 1. - Spawning stock and recruitment in Baltic cod (1973-1993) (ICES). Proposed model (Solari et al., 1997) (solid line); Shepherd (1982) (dashed line) and Myers (1995) (dotted line). a): slope in origin; b): fractal parameters. (after Solari et al., 1997).

the time variable into account. These two circumstances give the numeric expression more flexibility. It is necessary here to mention two other important aspects: If all the attractors of the diverse levels or balancing cycles are combined, a similar curve to that of Beverton-Holt is obtained, therefore the additive expression achieves a larger, more reliable $S / R$ expression throughout the various ecological states (temporal). Another important aspect is that the structure of the value of the constant $b$ has a fractal nature. This value corresponds to the state of the attractor in accordance with the value of the spawning stock. Therefore, the structure of the various cycles is maintained and the scale is the only variable that changes. The study carried out on the population changes of Micromessistius poutassou shows that the variations in the mean size continue to be similar although the mean level varies as a consequence of the higher fishing intensity. In this way the stability of the ecological structure is confirmed in spite of the external interferences, i.e. fishing. The situation that leads to stock collapse would only change if confronted with extreme variations.

\section{Stock evolution}

One of the most interesting problems is related to the evolution and control of the exploited resources. In general, collecting catch statistics has been the method used, as well as controlling and quantifying the fishing effort. However in few occasions has this information been used taking into account that this is demographic work. Collecting this type of infor- mation is fraught with difficulties both in relation to time and space. The ideal situation would be to cover a wide area over a long period of time with reference to the main species, but this is rarely possible. A series of strategies have been developed to obtain the most information possible in the simplest way. There are two basic strategies: The first is to simply collect information about the catches in the port where the fishing boats come in, it is rare that this strategy can be carried out in various ports at the same time and over a long time period. Bas et al. (2003), points out the importance of having long series of reliable data available, this requires a considerable effort. For this reason it is interesting to highlight the importance of fisheries studies for ecological research due to the large amount of data they provide (Margalef, 1974). The problem continues to be that the data is difficult to use and apply: short series, missing information and in general the data is unreliable. The other strategy that provides good information is scalable to a certain degree. The official information, which is always very unreliable, is used and compared with information obtained following more reliable, prepared strategies distributed over time and area (e.g. censuses in ports over adequate time periods). These prepared strategies provide information that can be used to correct and validate the official information. In this aspect, it is more useful and representative for analysing the stock evolution if the census is carried out in time periods that are especially important for the species, i.e. reproduction/recruitment (Calderón, 1987).

The studies are always demographic, an aspect which in some studies has not been taken into account sufficiently when analysing fisheries and the ecosystem to which the exploited resource belongs. The various studies show the impact of fishing on the conservation of the ecosystem (Bas, 2002, Pranovi et al. 2000; Koslow et al., 2000; Sánchez et al., 2004). From this we can deduce that it is essential to obtain information that is as reliable as possible.

\section{Carrying capacity}

The concept of carrying capacity is especially interesting for explaining the behaviour of natural systems that are being exploited. In the development of an individual or a system it constantly tends towards a limit, asyntotic value. This value cannot be exceeded unless the environmental conditions change substantially. In most analyses of this con- 


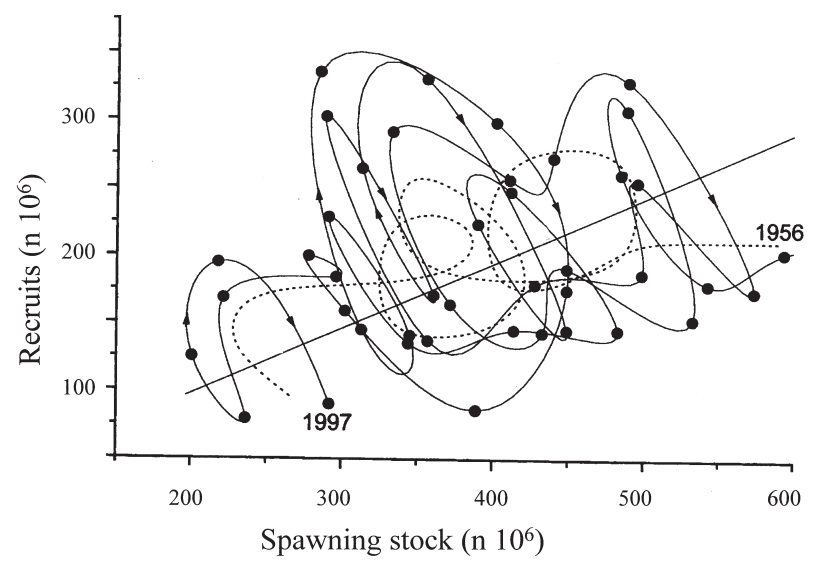

FIG. 2. - Stock-recruitment relationship in Icelandic cod (after Bas et al., 1999). In the Icelandic situation there probably is an influence of the very important changes in the environmental conditions resulting from the collision of the Inminguer current and the Polar current, probably with important consequences in the reproduction patterns and recruitment success.

cept the carrying capacity is considered to be a maximum value (biomass) that a particular species can reach in a certain ecologic context (ecosystem). However this evaluation can be misleading as this level depends precisely on the structural level of the particular ecosystem. Therefore, we can consider the carrying capacity to be the maximum value that the ecosystem can reach. The maximum value of the ecosystem's carrying capacity depends on the environmental conditions. In this case, the changes in the environment imply that we must consider the carrying capacity of the broader system in which the ecosystem is situated. It is convenient here to mention concepts that will be analysed further on, such as LME (large marine ecosystems) and, advancing even more, the Gaya hypothesis from a global perspective. In the case of fishery analysis concerning the state or assessment of a LME, it is believed that the carrying capacity should be considered and its variations represent the maximum level in the development of the system/resource that is being analysed. The most important thing is that the carrying capacity can vary and its variations represent a new state, positive or negative, of the expected biomass available to be exploited/fished. The existence of a maximum limit is evident, but the situation is more complex when we try to give a value to this maximum limit. It would seem that the overall productivity would be a good indicator, considering it as the starting point of the trophic chain in which the exploited resource is situated, although this could refer to different links of the chain. However, the same primary productivity depends on external factors, some that are more constant (temperature,

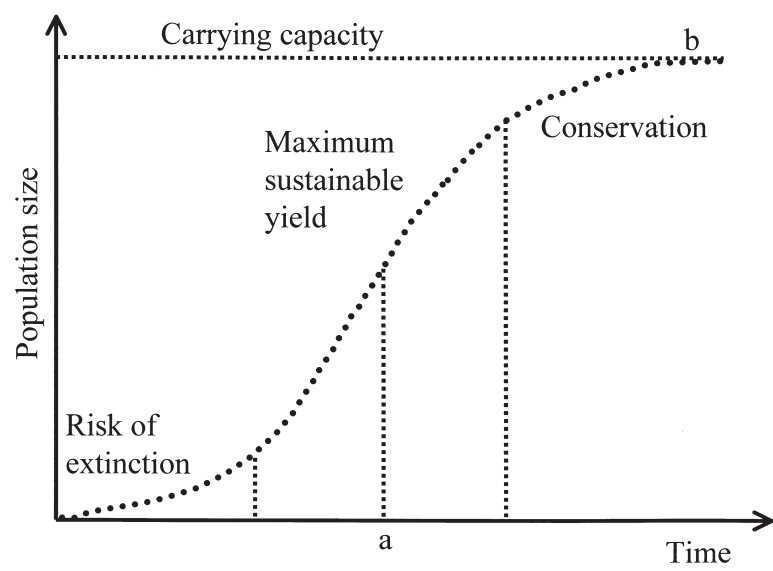

FIG. 3. - Logistic development curve of a population. The inflexion point corresponds to the change in the food consume/growth relationship. This point is an adequate reference to establish regulation strategies. a) inflexion point; b) carrying capacity. After Bas (1957) and Monte-Luna et al. (2004).

salinity), and others that occur periodically (winds, continental contributions), some are fluvial and others aerial. To estimate the factors that influence the overall productivity would help to estimate the system's carrying capacity and at the same time evaluate its changes. Figure 2 is a good example of how environmental changes (marine currents) influence the structure of the relationships between the spawning stock and recruitment.

Verhulst (1838) considered the carrying capacity as the maximum quantity of the resource that the system could support, keeping in mind that it is always finite due to the food, space, etc. available. This is expressed in a logistic curve. In this context various authors recommend placing the exploitation environment at half the asyntotic value or better still in the variation curve (Bas, 1957; Monte-Luna et al., 2004) (Fig. 3).

It is also important to consider the economic carrying capacity (Fig. 4). The concepts are not clearly defined. For Beverton-Holt it corresponds with the asyntotic value of the exploited stock. For Myers (2001) it corresponds with the equilibrium value with respect to the abundance of spawners. These states correspond to a wider vision that includes aspects related with the fractal character of nature (Caddy and Stomatopoulos, 1990). In the ECOPATH and similar models, the carrying capacity value is at the highest level. It is very interesting from a practical point of view to verify that in general in fisheries analysis the carrying capacity is considered as constant even though it is evident that significant variations exist (fluctuations). All this shows that ecosystems have a certain amount of elasticity, a concept which we will look at further on. 


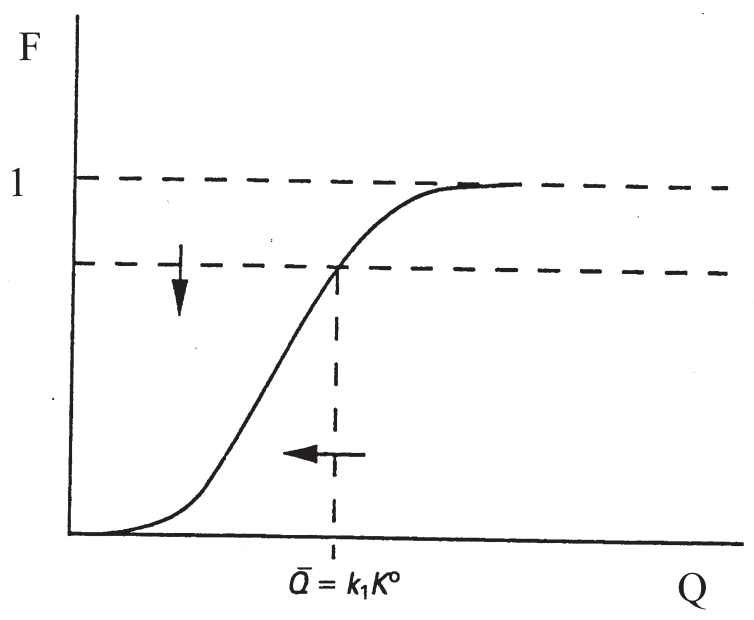

FIG. 4. - Cumulative probability distribution for the total allowable catch $(\mathrm{Q})$, and the optimum capacity $\left(\mathrm{K}^{0}\right)$. Arrows indicate the effect of a higher cost or a lower price and/or productivity.

Inverse density dependence (Courchamp et al., 1999)

This process has deserved little attention, however in many cases it explains the inefficiency of the management measures for very degraded areas. Figure 5 clearly shows the state the recruitment process can arrive at when there are excessively low levels of spawning stock. In this situation the phenomenon of density dependence leads to a state of collapse. This situation however needs to be described in more detail because in fishing exploitation the close relationship between ecology and economy is very important. According to the nature of this relationship, fishing stops earlier or later depending on the economic value. If the economic value is low, the decrease in the resource will force exploitation to stop, maybe when there are still significant levels of the resource, which will be able to recuperate. However, in fisheries in which the prices are very high the resource continues to be exploited even when the biomass level is extraordinarily low and as a consequence recuperation is a lot more complicated. This is the characteristic situation in many areas of the Mediterranean. Needless to say, subsidies in general make this situation worse. The inverse density dependence process is difficult to explain for some species but the Allee effect, mentioned above, can be considered as one of the causes of this situation.

\section{The influence of available space}

This concept has received little attention. Especially those species that expand or move to particular areas, as for example hake when they start their benthic phase in depths of around $100 \mathrm{~m}$. They migrate towards the slope where they complete their development until first spawning. In the cases when the continental shelf is very thin, during this agerelated migratory process the fish must move very slowly due to the narrowness of the shelf. This causes density dependence that is not connected with the

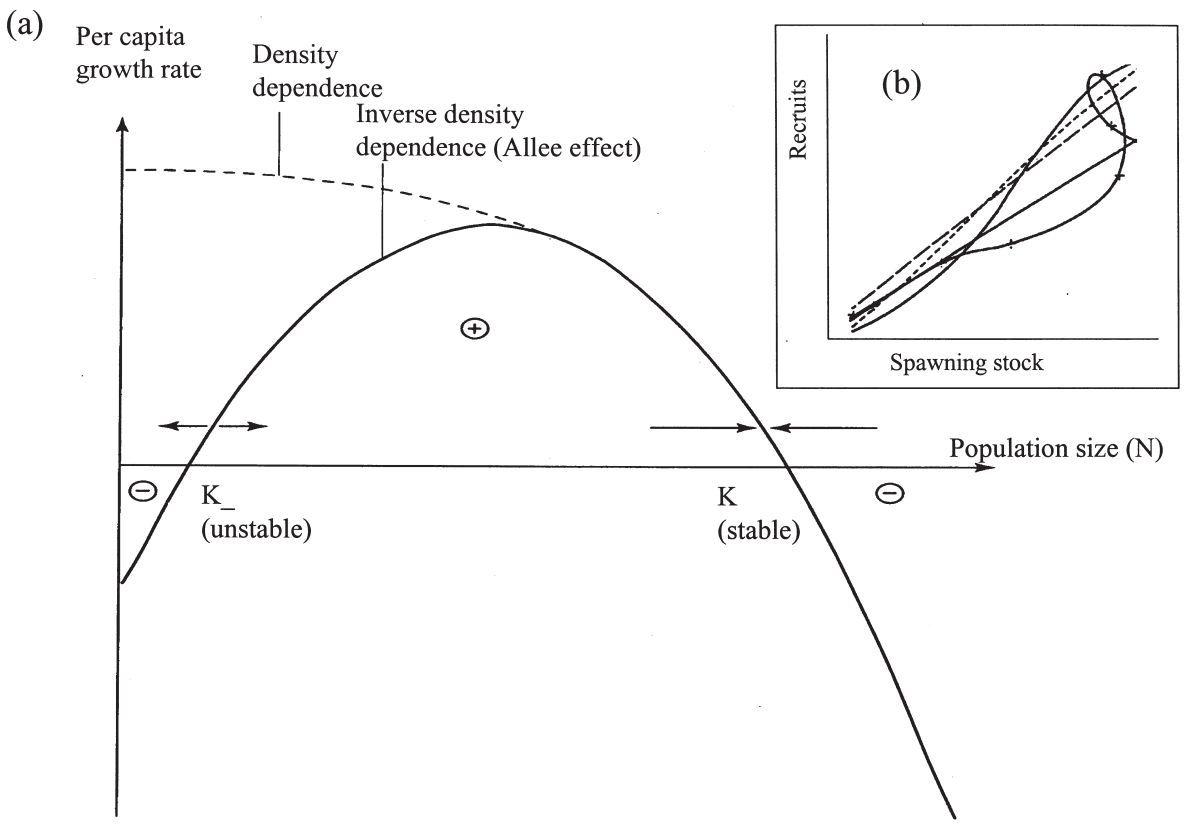

FIG. 5. - a) Illustration of the Allee effect, from a very simple mathematical model of population dynamics (Courchamp et al., 1999). b) Inverse density dependence in the reproduction/recruitment relationship (after Bas at al., 1999). 

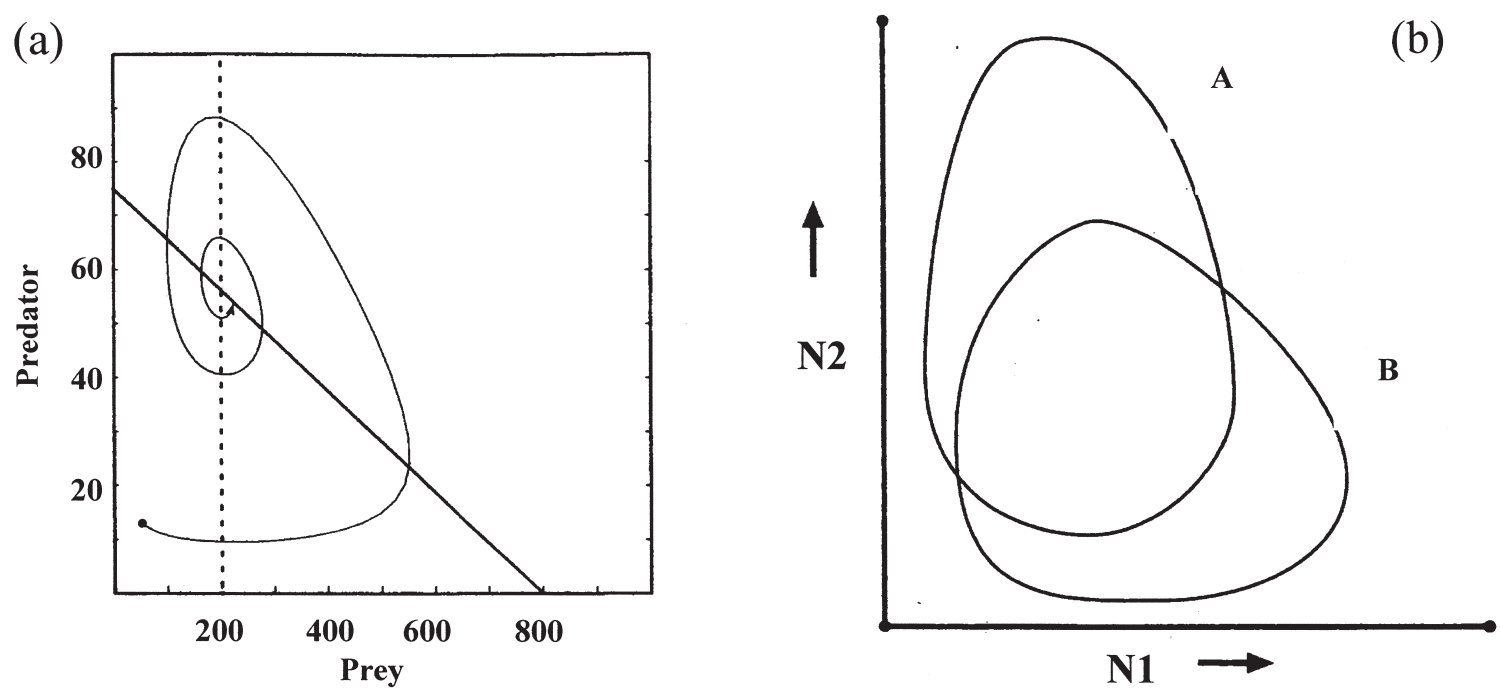

FIG. 6. - a) Zero-growth isoclines for the model of interacting prey and predator populations. The thin line is a trajectory predicted by the discrete-time per-capita trophic model in Lotka-Volterra-Nicholson-Baitey with logistic self-limitation on the prey (Barryman, 1992). b) Relation between prey and predator (after Margalef, 1974; D’Ancona, 1964).

actual density but rather with the space necessary to carry out the migration in a certain time determined by the age of the fish when it reaches the slope.

A similar situation is found in the insular shelf of the Canary Islands, which is extremely narrow with the slope located very close to the coast (Bas et al., 1995). In this shelf the possibilities of population development are directly related to the limited space available. In these cases it is necessary to consider that the limited space available influences the carrying capacity of the system, influencing some species especially and in particular those that are important for the fishing industry (Paine, 1966).

The predator-prey relationship (Barryman, 1992)

Applying the model postulated by Lotka and Volterra (Lotka-Volterra models) is based on the ideas generated from the law of mass action. It is not inconvenient to consider fishing (predator action of the fisher) as a predator stimulated by economic laws and incentives, given that humans (fishermen) are the most successful predators. Barryman (1990), suggested that it is better to use the concept of ratio dependence of the predator and prey derived from the logistic expression (Verhulst, 1838), than the simple predator-prey relationship. The logistic expression

$$
\frac{d N}{d t}=a N\left(1-\frac{N}{K}\right)
$$

where $\mathrm{N}$ is the biomass, the maximum rate of change per capita, and $\mathrm{K}$ is the equilibrium density, known as the carrying capacity of the environmental state. Although the logistic method appears to be stable, K can change (Bas, 1957). In a population that doesn't have predators population growth can be considered to be infinite. This is an unreal situation because predators always exist even though there may be few of them. In this case the most adequate equation would be:

$$
\frac{d N}{d t}=a N\left(1-\frac{N}{K}\right)-b N P
$$

where $\mathrm{P}$ is the predator. This situation always tends toward stability (Fig. 6). The first logistic expression referring only to the predator would be:

$$
\frac{d P}{d t}=e P\left(1-e \frac{P}{N}\right)
$$

(Leslie, 1948) where $e$ is the prey density necessary to maintain a predator and replace it through its offspring when it disappears. It is the marginal demand that assures the continuity of the predator; $1 / \mathrm{e}$ is the marginal value of the resource/prey's reproduction and N/e is the carrying capacity of the system when the quantity of prey remains constant. The relation

$$
R_{i}=\frac{1}{N_{i}} \frac{d N}{d t}=d \frac{\ln N}{d t}=\ln \left(\frac{N_{t}}{N_{t-1}}\right)
$$

is related with

$$
R_{i}=\frac{a_{i}-b_{i} N_{i}}{\left(w_{i-1}+N_{i+1}\right)}-\frac{C_{i} N_{i+1}}{\left(w_{i}+N_{i}\right)^{2}}
$$

where $b$ is the intraspecific feeding competence over the change rate per capita; $\mathrm{c}_{\mathrm{i}}$ is the vulnerability and 
$w_{i}$ is the biomass density of the rest of the species/food in the trophic level $i$-th. This structure that relates the different parameters and levels is connected with the well-known ECOPATH and ECOSIM models (Pauly et al., 2000).

We must keep in mind that ecologic systems are rarely in perfect equilibrium and the estimates are generally based on not very long series of data and mean values. The relationships, as indicated above, are better expressed by taking into account the reason for dependence rather than the traditional preypredator relationship.

The relationship between biomass and productivity, considering three balanced levels, corresponds to the following states: $P$ (plants, in the marine system basically plankton), $H$ (herbivores, zooplankton in the widest sense), and $C$ (carnivores, the highest levels in the trophic web). These states of equilibrium, that equal 0 , can be expressed with the three following formulas:

$$
R P-D P-f\left(\frac{P}{H^{\alpha}}\right) H=0
$$

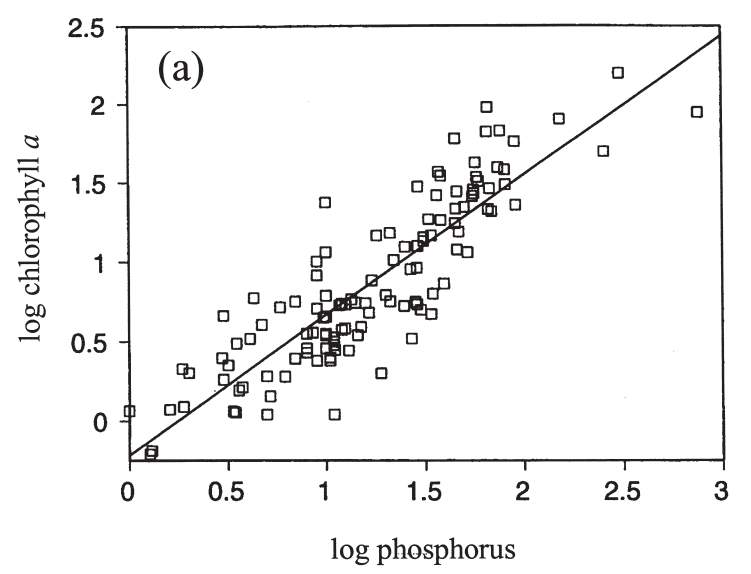

$$
\begin{gathered}
e_{h} f\left(\frac{P}{H^{\alpha}}\right) H-g\left(\frac{H}{C^{\beta}}\right) C=0 \\
e_{c} g\left(\frac{H}{C^{\beta}}\right) C-\mu C=0
\end{gathered}
$$

where $R$ is the primary productivity; $D$ the plant mortality rate; $f$ is the plant consumption rate caused by a typical herbivore, and $g$ is the consumption rate of herbivores consumed by a typical carnivore; $e_{h}$ and $e_{c}$ are the efficiencies of herbivores and carnivores (conversion of consumed material into reproduction); $m$ is the carnivore mortality rate; and $\alpha$ and $\beta$ measure the level of interference between predators while they consume the resource, i.e. the prey. In the classic predator-prey model, $\alpha=\beta=0$, and in the reason-dependent models $\alpha=\beta=1$ (Ginzburg and Akçakaya, 1992; Fig. 7).

The Lotka-Volterra (L-V) equation has a strong relationship with biodiversity. Wilson and Lundberg (2004), in a recent study analysed the interrelationship between the intraspecific and interspecific states. Based on the L-V model they studied interesting

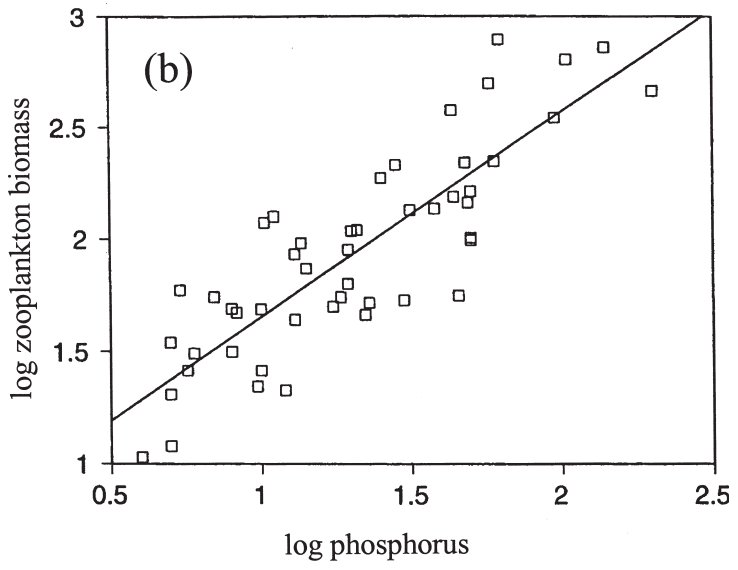

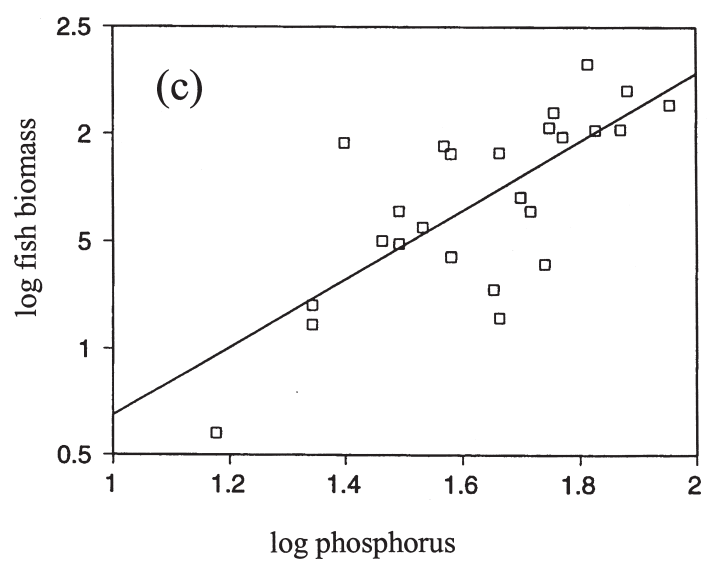

FIG. 7. - Several relationships between total concentration of nutrients (phosphorus, in $\mathrm{mg} / \mathrm{m}^{3}$ ) and chlorophyll $a\left(\right.$ density, in $\left.\mathrm{mg} / \mathrm{m}^{3}\right)$; zooplankton biomass (in $\mathrm{mg} / \mathrm{m}^{3}$ ) and log fish biomass (in kg/ha) (after Ginzburg and Akçakaya (1992), Jones and Hoyer (1982) and Hansen and Peters (1984)). 
aspects of the abundance distribution. This serves as a theoretic model of the properties of the open community to the different types of migrations. The first factors affect the interspecific interactions (Volterra, 1926), densities (Elton, 1930), the biological behaviour (Cole, 1954), and the species' habitat (MacArthur, 1958). It is important to keep in mind that any change experienced by a certain species within the ecosystem has clear repercussions for the rest of the species in the ecosystem. It is therefore only possible to understand both the strength and weakness of a system when it is stressed. We need to keep in mind that fishing can cause evolutional changes in the exploited species and as a consequence in the ecosystem (Stokes et al., 2000), through changes in the age composition, the size of first maturity, and possible changes in the fecundity rate. In this context the ECOPATH and ECOSIM models are without doubt very useful, although they are limited for many situations for want of adequate information when evaluating the different parameters in the system. The possibility of overcoming a state of collapse depends to a large extent not only on the characteristics of the fishing action but also on the characteristics of the exploited population and its ecological context. Therefore, certain environmental changes, an important one of which is fishing, influence the overall ecology and the evolution of the genotype of the affected stock. From this we can deduce that for correct stock assessment it is essential to have correct ecological information of the whole integrated ecosystem. We need to point out that in the deeper areas in which there is, according to the information we have, more stability and an equilibrium between the ecosystem's components, fishing action has notably damaging and destabilizing effects (Bas, 2002).

From an economic point of view of exploitation, and remembering that the fisher is the most efficient predator, it is only necessary to adequately reconvert the bio-ecological parameters mentioned above. It is expected that converting the biological parameters into economic situations that have there own laws ("economic laws") will allow us to formulate very efficient bio-economic models.

\section{STRATEGIES}

\section{Balanced and unbalanced states.}

In most situations in which it is feasible to study fishery impacts, it is accepted that the initial state of the system, whether considering only the exploited stock or the whole ecosystem, is in a stable state. However, examining the real situations shows that in most cases the system is unbalanced or at the limit. This is the most common state in population or ecological studies and it is precisely the limits between the balanced state and the unbalanced state that are very important aspects of the study, because they express the limits of both situations. In some ways the concept of vulnerability, cited above, is also related with this. Analysing the disturbances in the normal conditions of bio-ecologic behaviour is very important and can provide a lot of information in relation to the concept of the system's elasticity. This concept will be considered further on.

\section{Always in the context of the ecosystem}

Most of the strategies employed in fishery analysis, both for assessment and management, as well as the model's structure (production, analytical etc.) do not take into account the overall context in which the exploited stock is situated, centring all attention on the stock. It is true that the most recent concepts such as ECOPATH, ECOSIM, etc. try to evaluate the interrelations between the different components of the whole, with special attention only to the relationships between the components of the trophic chain. However, it is important to consider that the exploited stock forms a structural part of an ecosystem, not only as a link in the trophic web, but also interrelated with the whole system through multiple interactions (available space, competition for food, various relationships with the environment, different reaction capacities, etc.) that affect the stock because they affect the ecosystem. As a consequence, any strategy aimed at preserving and sustaining the exploited resource needs to be developed keeping in mind the overall alterations in the ecosystem. Doing this is the only way to preserve the stock in conditions of maximum stability, and this stability can only be provided by the healthy condition of the ecosystem as a whole. On the other hand, the state of maximum potentiality can only be reached when the ecosystem has optimal health that in some ways represents the maximum carrying capacity and therefore permits the maximum expansion and stability of the exploited stock.

\section{The uncertainty principle}

The concept of uncertainty is a familiar concept in the understanding of ecosystems. It relates to different situations which present certain difficulties, 


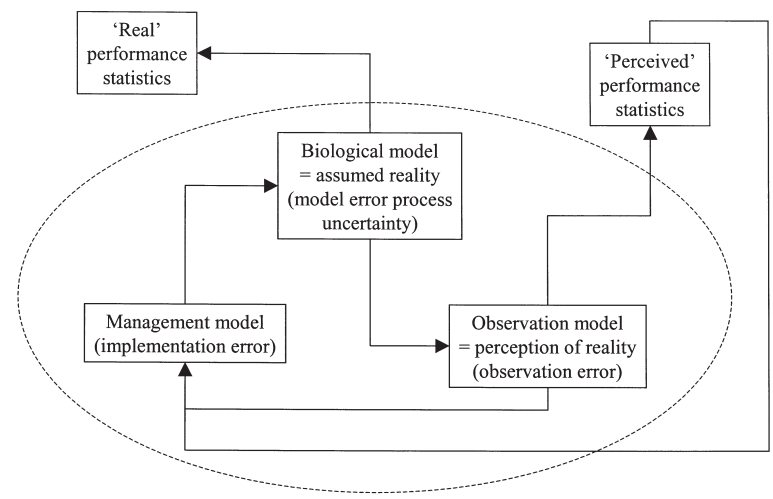

FIG. 8. - Several sources of uncertainty are represented in an operating model framework (after Hardvood and Stokes, 2003).

such as: obtaining sufficiently correct measurements that are representative, and accessing data collected over an adequately long period of time that reliably represents the process. From the point of view of fishery management, the uncertainty principle has given rise to precautionary behaviour models that are useful because they smooth over the effects of the state of uncertainty and risk. They modify in favour of reducing fishing pressure by taking precautionary measures. In this type of analysis either the situations are simplified or they generate a high information risk level, i.e. uncertainty. The information is simplified in relation to its character, a part of which is ignored resulting in the simplification. In fact certain information is disregarded as such. This situation not only occurs in the biological sciences but also in other disciplines, especially in relation to the economy, which is a very important component of the fishery strategy. It is very useful in this situation to keep in mind a certain level of precaution. Precautionary policies should take into account the social and economic consequences as well as the environmental ones; therefore the policy acquires a wider meaning beyond the basic bio-ecological aspect. It is integrated into the ecologic aspects in the broadest sense, considering both the environmental factors and the fishing factors (sociology and economy). In this aspect, introducing the socio-economic parameters increases the level of uncertainty due to the typically human nature of these factors (Fig.8).

The difficulties or sources of uncertainty in biological studies result from the problems associated with assessing growth in the factors of reproduction, mortality and migration processes etc.. As well as the degree to which these factors are affected by the size changes of the population or by environmental changes, these aspects are related, to a certain degree, to the system's carrying capacity. A clear example is the distribution of the different species of bream, Pagellus erythrinus and Spondyliosoma cantharus, on the Saharan coast. This example shows the differences between the species and age distribution in the real population and the samples obtained through catches, even when they are scientific samples. In this context it is preferable to have a scenario which, still keeping in mind some inadequacies, adapts to all the levels of the system which is being studied/modelled, rather than a perfect scenario that can only be adapted to some situations. It is a sad fact that the data provided by fishery analyses are not used to their full potential by ecological studies, in the same way that fishery studies seem to give little attention to the fundamental fact that the study is a particular aspect of ecological research. Better use of the statistical principles developed by Bayes would allow the estimates of the different parameters to be compared, reducing the risks of evaluating them, and at the same time work with heterogeneous data.

However, one thing is the assessment of biological potential and another thing is the way in which the different parameters with a high degree of uncertainty are treated in predictive models and behaviour (Hilborn and Walters, 1992), both in relation to the exploited species and fishing actions. The degree of uncertainty doesn't take into account what causes this high level of insecurity.

In the situations that result from unmanaged fishing activity (Fig. 9) we can observe how the param-

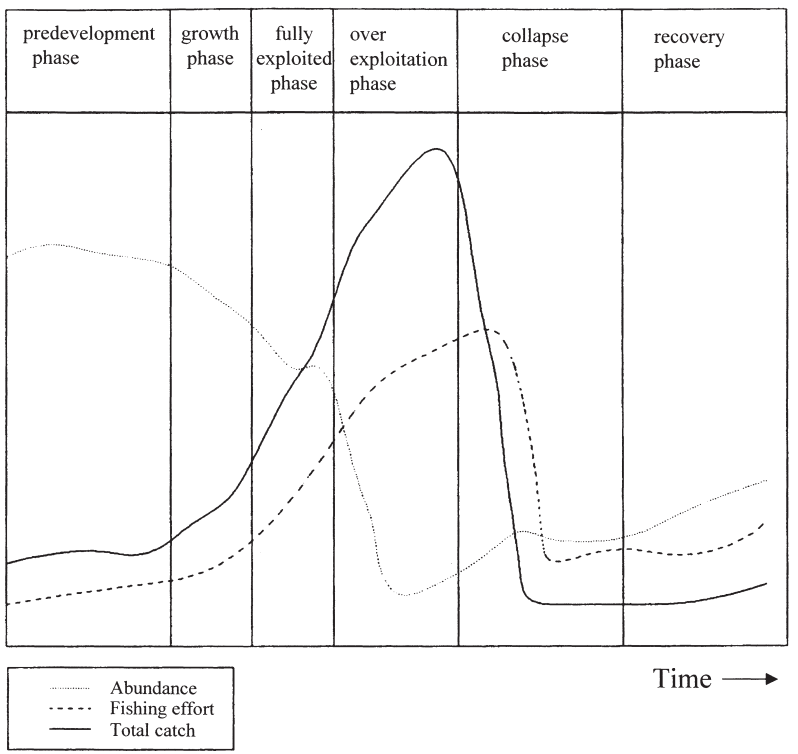

Fig. 9. - Phases of development of uncontrolled fisheries (after Csirke and Sharp (1984) and Hilborn and Walters (1992)). 
eters (biomass of the exploited population, developed effort and catches made over time) generally vary. However, there are numerous examples in which this behaviour shows distortions that could be caused by sudden changes in the environment or in the characteristics of the socio-economic parameter that, for example in the Mediterranean, has a decisive role in compensating for the decrease in the CPUE, which is always better than using the total catches for the continuous price increase of the species caught. This situation is another significant source of uncertainty in relation to managing fisheries (Harvood and Stokes, 2003).

\section{Analysis of elasticity in ecosystems}

It is possible to predict likely changes in populations exploited by fisheries by knowing the selectivity of the fishing gear and the demographic character of the exploited population. From this information it is possible to make recommendations for fishery management. In this context it is very important to make databanks of basic information (Froese and Pauly, 1997), of the demography of the planet's biodiversity. A system's elasticity allows us to compare the impact of the changes in parameters such as the survival index, growth or reproduction capacity in particular lifecycle stages, as well as the proportional contribution of the changes of the different lifecycle states related with population growth rate $(\lambda)$. In this order of things, biological evolution is related to demography. The elasticity concept has gained interest as an assessment value because it is easy to calculate and is connected with empirical data. As mentioned above, it is closely related to demographic changes and this could be connected with the fractal structure of this parameter in a similar way to the population recruitment model. The capacity (elasticity) of an ecosystem is measured by its capacity to withstand changes such as fertility and juvenile/adult survival without the characteristics of the system being destroyed. As an immediate consequence, a population with a high elasticity rate can endure high fishing pressure without serious consequences. However, the opposite is true for systems with low elasticity rates. This situation is related to the dominance of certain species in the ecosystem. According to whether the species have a fast growth rate or a slow one their elasticity will be higher or lower, respectively. Evaluating these parameters according to their relationship with elasticity presents some difficulties, however, they provide valu- able information for population assessment. An important example is the population changes of blue whiting Micromessistius poutassou in the Mediterranean. This population's behaviour shows rhythmical, periodical changes (about every eleven years), however, the influence of a strong fishing pressure since 1960 , although it has influenced the annual mean length, hasn't modified the population's structure due to its high degree of elasticity (Bas and Calderón, 1989). When we consider these aspects we need to take into account the existence of an unbalanced density with variations in the density dependence value, or independently, the uncertainty related to the estimated parameters mentioned above, such as population size. All of this is important in the management, control and conservation, in particular, of endangered species (Hepell et al., 2000).

The sensitivity and elasticity in reality explore the functional dependence $\lambda$ in relation with the liferate as a prospective vision. If the analysis is retrospective, the changes observed are expressed in the value $\lambda$ (elasticity) as a function of the (co)variance of the liferate, which can be useful for managing the periods of change in the ecosystem. In the population development, $\lambda$ is a function of the liferate. The elasticity is used to quantify the transition rate in the projection matrix over the population growth rate $\lambda$. In the recruitment model explained previously, the elasticity would be related with the changes between cycles (density dependent states) (Solari et al., 1997; Bas et al., 1999).

\section{MANAGEMENT AND RECUPERATION ASPECTS.}

\section{Final results, mechanisms and opportunistic species}

The most modern approaches to resource management lead to reconstructing the target species' ecosystem. However, the great complexity of the situations that interrelate the components of the ecosystem make reconstructing it considerably complicated (Pitcher, 2001). From the point of view of correct fishery management, the problem is closely related with the possibility of recuperating the biomass level of the fished species, the target species. On many occasions the measures aimed at reconstructing an ecosystem altered by fishing achieve a certain level of success, but there is no guarantee 
that the target species, which was a significant fraction of the overall biomass, will be able to recuperate. It is more likely that its ecological space will be occupied by another species with higher possibilities of success in the new context, for example, an opportunistic species with a high adaptation capacity. A clear example appears in the analysis of fishery resource exploitation in the Canary-Saharan bank. The initial massive exploitation led to the practical extinction of the target species: bream. Its elimination and the fishing regulations did not allow it to recuperate, its space was quickly occupied by an opportunistic species, the octopus, which has a high growth capacity and is the normal prey of bream. From an economic point of view, this process generally leads to the catch losing value. In this specific case, octopus fortunately has a higher value, so the change has turned out to be economically positive. This aspect from the bio-ecologic point of view may seem of little importance, but it is very important from a fishery point of view which, as we know, includes economic factors.

Reconstructing profoundly altered ecosystems, as in the case of the ecologic environment of cod populations (Gadus morhua) or bream/cephalopods populations in the Saharan bank, is extremely difficult. Various authors (Odum, 1959; Ludwig, 1999; Pauly et al., 2000), have suggested mechanisms which relate with changes in the ecosystem. A suggested strategy is to designate large marine reserves that are absolutely "reserved", and at the same time encourage the reintroduction of species which were previously endemic to the ecosystem. A practical example is the marine triangle whose vertices are the Medas Islands, the Cabrera Island and the Tabarca Island. Each corner is a totally protected area and the combination of the three corresponds to the expansion zone.

A basic strategy is based on learning about the past and its evolution, and projecting this evolution on the current modern situation as well as applying it to the future. The question is the following: What do we know of the past that has led us to our unfortunate current situation? The biodiversity and integrity of the ecosystem have been strongly eroded away (Pitcher, 2001). When we consider and analyse fishing action it is imperative to take into account that the aims of economic, social and ecological stability are very rarely compatible in practise. To be able to reconstruct the past and project it on the future implies understanding the local ecology (LEK, local ecological knowledge) and the tradi- tional environment (TEK, traditional environmental knowledge) (Fig. 10).

\section{Analysis of the LME (Large Marine Ecosystems) concept (Sherman and Duda, 1999)}

The concept of an ecosystem is generally quite well explained, but when we try to include in this concept the diverse aspects that characterise fishing, defined as the action of humans on marine resources, the explication is more complex. It is in this context that the concept of Large Marine Ecosystems is useful. This concept implies not only considering the ecosystem in the strictest sense as the context in which the exploited stock is located, but also including all the aspects that are in some way related with fishing. So that economic aspects have to be considered because economy and sociology are basic elements of the fishing process. In this sense, the structure of the littoral and pre-littoral areas is important because they provide the conditions, for example, for port structures or beaches that are appropriate for disembarking boats, and the possibility to construct markets or fishery communication systems. On the other hand, the LME concept implies understanding environmental fluxes, marine currents, nutrient inputs and the influence of rivers, wind, and meteorology in general. The marine dynamic is not only responsible for the sea's productive capacity but also regulates the presence and abundance of the different species among which are the exploited species (target species). The vast amount of information required to explain a LME appears to be too complicated for it to be feasible and in other cases it remains too diffuse. However, this concept is broad enough to be a base for understanding the whole fishing process because it allows us to include both bio-ecologic and socio-economic strategies in a sufficiently large and well-defined context, especially in its geomorphologic structure. An excellent example is the Mediterranean (Caddy, 1993; Bas, 2002). The possibility of integrating oceanography and meteorology in a well-defined geomorphologic context gives rise to a biologic/productive strategy (primary productivity) which is very characteristic, and as a consequence is characteristic of the fishing production. The existence of uniform characteristics, although with clear gradients, allows us to identify the behaviour of this large marine ecosystem. Together with the bio-ecologic behaviour there is a socio-economic strategy that has clear connotations for the Mediterranean, both 
for the target species and for the sales and product use strategies in most cases.

The panoramic study of the world's oceans and seas leads us to recognise a certain number of LMEs although in general they are less well defined than the above example of the Mediterranean.

\section{IMPORTANT CONCEPTS AND USEFUL} TOOLS FOR ANALYSING AND MANAGING EXPLOITED ECOSYSTEMS. SUGGESTIONS.

\section{Fuzzy sets}

Fuzzy sets will definitely become very important in the numeric treatment of the processes related with resource exploitation (Trillas, 1980). These concepts derive from the logic of Boole related with the functional logic of uncertainty. Evidently we will not try to explain the fuzzy set concept here but simply point out the convenience of exploring it, since a large number of biological, ecological, economic and social situations, all closely related with fishery science, could benefit considerably from the ideas provided by fuzzy sets. The possibility of defining areas of limits and textures that are not defined exactly (fuzzy sets) is particularly useful, and especially the possibility of using fuzzy sets in a similar way to how defined sets are used. In reality in the recruitment process model, each of the sets derived from the density-dependent processes can be considered as a fuzzy set, although in this case as mentioned above, it is in fact a state of chaos that is defined or governed by a particular attractor.

\section{Chaos analysis}

Analysing chaos, or chaotic states, is directly related with the circumstances pointed out in the previous section -fuzzy sets. Here, the chaotic system will simply be defined as a disordered state (undeterminable situations) within an order (the defined concept). Most of the situations that characterize fishery studies fall within this context. In reality, the state of the points that refer to any process is not defined but rather is approximated within a certain context. This context is always sufficiently well defined and corresponds to the model used, whichever model it is. For production models as well as analytic or recruitment ones it is impossible to accurately establish the relationship between a pair of given values, however it is possible for the context in which they are located. The importance that is currently given to the uncertainty principle is closely related with the treatment of chaos. Using the recruitment model once again, each of the cycles determined by the density dependence can be considered as a chaotic set limited by the maximum carrying capacity in each situation. These limits are what put order, limit or environment, in the chaotic set that determines each situation. Sell (1984) introduced the attractor concept into the chaotic system. As indicated before, this concept is very important. In a model with successive ecologic states, each with a chaotic structure, the set of attractors summarises the simple model commonly used. This analysis allows us to obtain more detail when representing the model or process. These attractors can be periodical or semi-periodical (Sole and Manrubia, 1996), but in any case they define the system's state topographically. In the case that is used as an example, the system's state is characterised by a densitydependent process (Haken, 1984; Shaw, 1984).

\section{Fractality concept}

Another important aspect is the concept of fractality. Since this new vision of geometry, fractal geometry, has been developed it has been applied extensively in the process of understanding many ecologic processes (Jürgens et al., 1990). It would therefore be interesting to go into more depth not only to understand the concept better but also to apply and develop it. The development of forms (morphology) both for the exploited species as well as, for example, the relationship between length and weight (Safran, 1992), and other structures are characterised by their fractal nature. But here we must mention again the recruitment model developed by Solari et al. (1997). In this case, the constant $b$ that corresponds to the state of the density dependent relationships expressed by their corresponding attractors, definitely has a fractal structure, since it relates with the variations in scale of the different recruitment phases, characterised by a progressive increase in the variation field as the size of the spawning stock increases. Therefore, it is evidently a clear relationship between fractality and the state of chaos that exists between each of the states and cycles in the recruitment model. This is important inasmuch as the spawning/recruiting structure doesn't vary in behaviour, although it does increase the size of the chaotic area, which is progressively larger. It is also important because it shows clearly that nature does not work according to chance, basic ele- 
ments exist that do not change even though the scale varies. An example of this order/chaos relationship is the Mandelbrot set (Mandelbrot, 1983), in which the limit point always remains the same. In the recruitment model, the state of the attractors represents the limit point, which corresponds with the more simple models (Ricker, Beverton-Holt, etc.) (Barnsley, 1988). Another recent example appears in the comparative study of fishing behaviour of some tuna fisheries in three areas with progressive scales in the central-east Atlantic (Solari et al., 2003). The behaviour is the same although the spatial scales are different: fractal structure.

\section{Evolutional and Darwinian aspects of fishing action}

The strong demand for fishery products means that different disciplines need to be coordinated, ranging from physical oceanography, biology and ecology, with special attention to evolution ecology. All of these are pressured by fishery economy and sociology, making it imperative to develop fishery control and management policies that are as correct as possible. At first it was believed that the sea was inexhaustible. Suau (pers. comm.), after attending a congress on new fishing technology, commented that unfortunately while some scientists aim at understanding and managing stocks others propose new fishing techniques that are more and more efficient for catching the species. As a consequence, currently most stocks are over exploited and others have clearly collapsed. In a stable or semi-stable state, selection is in favour of those species that, due to their number of offspring, assure the state of their spawning stock. Therefore, the age at which first maturity occurs is more important than the fecundity level of the species. The primary factors that affect population growth must be considered to be very important, i.e. the interspecific interaction (Volterra,1926), density (Elton, 1930), biological aspects (Cole, 1954) and habitat (MacArthur, 1958). In this aspect it is important to consider not only the target species but also the other species in the ecosystem. We should point out that the worrying state of a stock is only evident when the situation is serious. It seems evident that fishing affects ecologic structures in the sense of an evolutional change through the changes to age structure and first maturity and perhaps fecundity (Law, 1979; Bas, 1998). This situation is related with the recuperation capacity of a species after a state of collapse, which is lower with an increase in the first age of maturity, a decrease in the age structure and changes in the competitors. It can be expected that the fishing action together with other environmental factors influence genetic modifications. It is difficult not to admit that these studies shouldn't be included in the context of knowledge or assessment of stock (Hutchings, 2000). Fishing activity eliminates some individuals and we can ask ourselves if those that survive the destructive forces are more resistant and as a consequence will proliferate in the successive generations (Conovar, 2000). Considered from the evolutional point of view, fishing is a massive uncontrolled experiment in evolution selection, clearly expressed by genetic variation. This is evident in large-scale exploitation and these changes are lasting and difficult to explain (Sinclair, 1999).

In the last instance, the possibility of carrying out fishing action depends on the carrying capacity of the environment in terms of biomass. The productivity of the population is density dependent and responds positively to fishing power. From the point of view of fish population, human activity represents a change in the environment that is neither unnatural nor infrequent, and is related with the growth rate's capacity to evolve. However, more rigorous studies are necessary. The alterations that can result from fishing action are not recuperated automatically when fishing stops and returning to the previous genetic conditions can require a long time period. The problem for Darwinian fishery management consists in determining which fishing gear would cause the least reduction in the adjustment, considering that a reasonable catch is made. Evolution effects caused by fishing have to be included in our thinking. Unfortunately, scientists and people in charge of management are under a lot of pressure from the immediate situations, so that long-term situations are considered to be a question of luxury.

The wide expansion and acceptance of the uncertainty concept is a response to the awareness of the insecurity related to the information. The practical vision is the modern recommendation to practice fishing within reasonable limits, in an attempt to counteract the level of uncertainty. It is possible that the development and application of the concepts commented on here will permit the development of more realistic models and simulations.

Natural selection influences the relationship between stock, spawners and the number of recruits (Walters, 2000), without forgetting what can be 


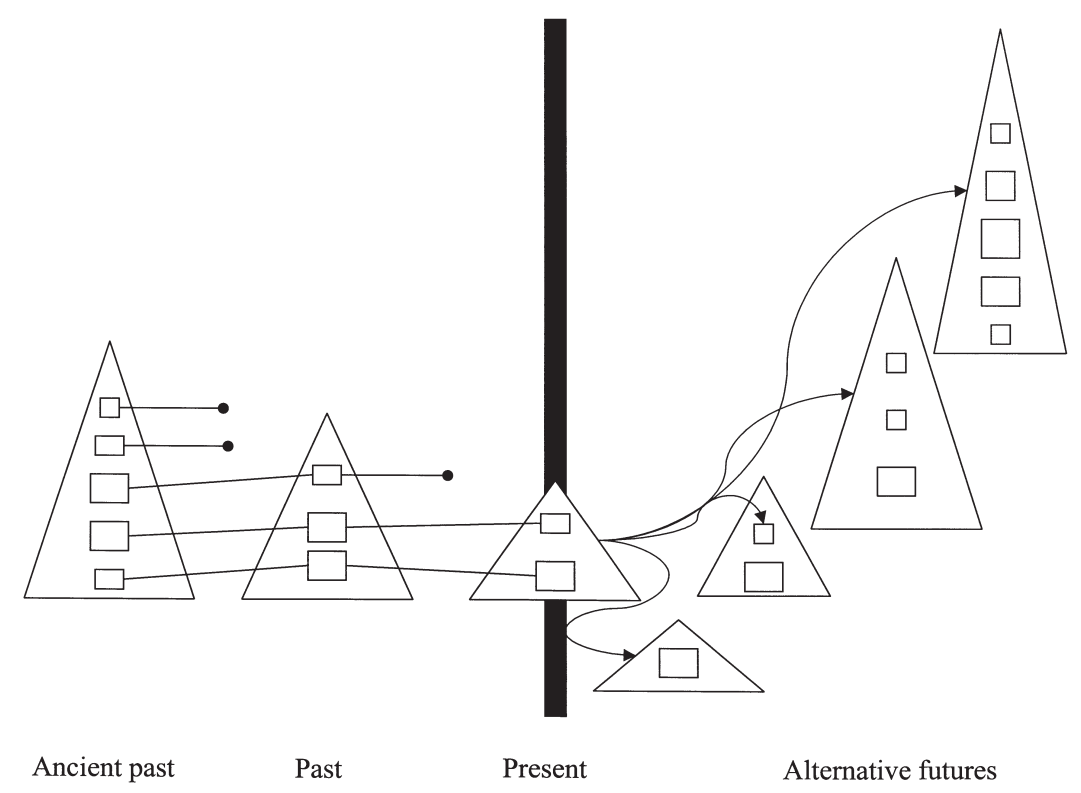

FIG. 10. - Diagram illustrating the "Back and Future" methodology for the evaluation of past ecosystems to the present situations and the future possibilities. Triangles, related with biodiversity level; squares, related with the several components of the ecosystems (ECOPATH models) (after Pitcher, 2001).

termed as compensatory mortality. Foraging behaviour influences this aspect. It is interesting to note the number of empty stomachs that are observed when studying a sample of fish, independent of the amount of food available. The impression is that the fish consume less than what would be experimentally expected. In this sense the intraspecific competence intensifies in the foraging areas where a species feeds (Fig. 10). In the large concentrations of Cape hake (Merluccius capensis) we can observe fluctuations in density, the areas with a higher density are related to the higher abundance of food in this area. This behaviour varies greatly and is related to how long there is a high concentration of the hake's prey. The hake fishing fleet can be represented by the aggregation pattern described.

When the production of juveniles is very high, growth is usually slower and the pre-recruitment process longer than usual, which implies that they are exposed to a higher mortality rate. Some authors consider this situation to be a consequence of a lower carrying capacity. This is definitely not so, it is rather the result of strong density dependence. This type of circumstance can be observed in young hake (Merluccius merluccius) in the narrow continental shelf in the Mediterranean. Also in this case, although two species compete for the same food in the same area, this doesn't imply the extinction of one of the species, due to their different feeding behaviour. In the same way, some sea-bottom species have a particular prey, such as benthic crus- taceans, including some that live half buried (Alpheus glaber), and others prefer the migrating euphausiid (Meganyctiphanes norvegica). The ECOPATH and ECOSIM models, among others, are closely related with all these strategies (Walters et al., 1997).

In this context it can be considered that the species that resist fishing action have a genotype that favours this capacity to resist. The population production includes an energy flow that is related with the carrying capacity in terms of biomass. The population productivity is density dependent and responds positively to fishing. Fishing activity in the schools of cod in Greenland resulted in an increase in the growth rate in its initial stages. The author considers that natural selection improves the possibility of success with respect to the long-term effects and changes resulting from fishing, contributing to the development of genetic structures that are less vulnerable. Fishing action implies a change of state, somewhat similar to environmental change. Therefore, fishing could favour Darwinian development in population evolution.

\section{REFERENCES}

Allee, W.C., O. Park, A.E. Emerson, T. Park and K.P. Schmidt. 1949. Principes of animal ecology. W.B. Saunders, Philadelphia,

Barnsley, M. - 1988. Fractals everyhere. Academic Press, London. Berkeley, S.A., C. Chapman and S.M Sograd. - 1988. Maternal ages as a determinant of larval growth and survival in a marine 
fish Sebastes melanops. Ecology, 85(5): 1258-1264.

Barryman, A.A. - 1990. Population analysis system. POAYS Series 2. Two-species analysis (version 1,0) Ecological systems analysis. Pullman, Washington,

Barryman, A.A. - 1992. The origen and evolution of predator-prey theory. Ecology, 73(5): 1530-1535.

Bas, C. - 1957. Barcelona y la pesca catalana. Cátedara Ciudad de Barcelona, Barcelona.

Bas, C. -1995. La pesca en Canarias y area de influencia. Ed. Cabildo Insular de Gran Canaria, Las Palmas de Gran Canaria.

Bas, C. -1998 . Overview on the biological aspects of recruitment. Report from the Workshop: A new non-linear model for $S / R$ and management fish stocks. Las Palmas de Gran Canaria. $31, \mathrm{III}-2, \mathrm{IV}$.

Bas, C. - 2002. El Mediterráneo: recursos y explotación. Ariel, Barcelona.

Bas, C. and L.E. Calderón. - 1989. Effect of anthropogenic and environmental factors on the Blue Withing Micromesistius poutassou on the Catalonian coast (1950-1980). Mar. Ecol. Prog. Ser., 54: 221-226.

Bas, C., A.P. Solari and J.M. González-Martín. - 1999 Observations over a new recruitment model for exploited fish populations. Mem. R. Acad. Cienc. Arts Barcelona, 960 V 58(5): 1-29.

Bas, C., F. Maynou, F. Sardà and J. Lleonart. - 2003. Variacions demogràfiques a les poblacions d'espècies demersals explotades als darrers quaranta anys a Blanes i Barcelona. Inst. Est. Cat. Arx. Sec. Ciènc., 135: 1-202.

Bethke, E. - 2004. A simple general approach to codend selectivity of trawls and its application to the data of Fiorentino et al. 1988 of hake (Merluccius merluccius). Fis. Res., 70(1): 113-119.

Beverton, R.J.H. and S.J. Holt. - 1957. On the dynamics of exploited fish populations. Fisheries Investment. Serie 2. Vol. 19. U.K Ministry of Agriculture and Fisheries, London.

Caddy, J.F. - 1993. Contrast between recent fishery trends and evidence of nutrient enricment in two large marine ecosystems: The Mediterranean and Black Sea. In: K. Sherman, L.M alexander and B.D. Gold (eds.), Large Marine Ecosystems: Stress, Mitigation and Sustainability, pp. 137-147. American Association for the Advancement of Science, Washington.

Caddy, J.F. and C. Stamatopoulos. - 1990. Mapping growth and mortality rates of crevice dwelling organisms onto a perforated surface: the relevance of "cover" to the carrying capacity of natural and artificial habitats. Est. Coast Shelf Sci: 31: 87-106.

Calderón, L.E. - 1987. Modelo de crecimiento de la bacaladilla, Micromesistius poutassou del Mediterráneo occidental y su relación con el ambiente. Ph.D. Thesis, Universitat Politècnica de Catalunya.

Cole, L.C. - 1954. The population consequences of life -history phenomena. Q. Rev. Biol., 29: 103-137.

Conover, D.O. - 2000. Darwinian fishery Science. Mar. Ecol. Prog. Ser., 208: 303-307.

Courchamp, F., T. Clüttobroek and B. Grenfell. - 1999. Inversedensity dependence and the Allee effect. Trends Ecol. Evol., 14(10): 405-410.

Crutchfield, J.A. - 1979. Economic and social implications of the main policy alternatives for controlling fishing effort. J. Fish Res. Bd. Can., 36: 742-752.

Csirke, J. and G.D. Sharp. - 1984. Reports of the expert consultation to examine changes in abundance and species composition of neritic fish resources. FAO Fish. Rep., 291: 1-102.

Elton, C. - 1930. Animal ecology and evolution. Clarendon Press, London.

Franquesa, R. - 1996. Heures: A bioeconomic model for management based on the control of effort. CEMARE Misc. Publ., 33 45-66.

Froese, R. and D. Pauly. - 1997. Fish-Base 97: Concepts, design and data sources.

Ginzburg, L.R. and H.R. Akçakaya. - 1992. Consequences of ratio dependent predation for steady state properties of ecology systems. Ecology, (73/5): 1536-1543.

Gordon, H.J. - 1953. An economic approach to the optimum utilization of fishery resources. J. Fish. Res. Bd. Can., 10: 442-457.

Graham, M. -1935 . Modern theory of exploiting a fishery application to North Sea trawling. J. Cons. Int. Explor. Mer., 10: 264-274.

Haken, H. - 1984. Chaos and order in nature. Springer Verlag, Berlin

Hanson, J.M. and R.H. Peters. - 1984. Empirical prediction of
Crustacean zooplankton biomass and profundal macrobenthos biomass in lakes. Can. J. Fish. Aquat. Sci., 41: 439-445.

Harvood, J. and K. Stokes. - 2003. Coping with uncertainty in ecological advice: lessons from fisheries. Trends Ecol. Evol., 18(12): 617-622.

Hepell, S., C. Pfister and H. De Kroon. - 2000 Elasticity analysis in population biology: methods and applications. Ecology, 73(5):1535-1543

Hilborn, R. and C.J. Walters. - 1992. Quantitative fisheries stock assessment. choice, dynamics and uncertainty. Chapman and Hall, New York.

Hutchings, J.A. - 2000. Numerical assessment in the front seat ecology and evolution in the back seat : time to change drivers in fisheries and aquatic sciences? Mar. Ecol. Prog. Ser. 208: 299-303.

Jones, J.R. and M.V. Hoyer. - 1982. Sportfish harvest predicted by summer chlorophylla concentrations in midwestern lakes and reservoirs. Trans. Am. Fish. Soc., 111: 176-179.

Jürgens, H., H.O. Peitgen and D. Saupe. - 1990. El lenguaje de los fractales. Inv. Cienc., 169: 46-57.

Koslow, J.A., G.W. Boehlert, J.G.M. Gordon, RL. Haedrich, P. Lorance and N. Parin. - 2000: Continental slope and deep-sea fisheries: implication for a fragile ecosystem. ICES J. Mar. Sci., 57: 548-557.

Law, R. - 2000. Fishing, selection and phenotypic evolution. ICES J. Mar. Sci., 57: 659-668.

Leslie, P.H. - 1948. Some further notes on the use of matrices in population mathematics. Biometrica, 35: 213-245.

Lotka, A.J. - 1925. Elements of physical biology. Williams and Wilkins, Baltimore.

Ludwig, D. - 1999. Is it meaningful to estimate a probability of extinction?. Ecology, 80: 298-310.

Lleonart, J. and B. Roel. - 1982. Evaluación del poder de pesca de las barcas de arrastre en algunos puertos de la costa catalana (sectores 37, 1-1 y 37, 1-2). FAO Rapp. Pêches, 270:1-83.

MacArthur, R.H. - 1958. A note on stationary age distributions in single species populations and stationary species. Ecology, 39: 146-147.

Mandelbrot, B.B. - 1983. The Fractal Geometry of Nature. W.H. Freeman and Co, New York.

Margalef, R. - 1974. Ecología. Omega, Barcelona.

Monte-Luna, P., P.W. Brook, M. J. Zetina-Rejon and V. H. CruzEscalona. - 2004. The carrying capacity of ecology. Global Ecol. Biogeogr. 13(6): 485-495.

Myers, R.A. N.J. Barrowman, J.A. Hutchings and A.S. Rosenberg. - 1995. Population dynamics of exploited fish stocks at low population levels. Science, 269: 1106-1108.

Myers, R.A., B.R. Makenzie, K.G. Bowen and N.J. Barrowman. 2001. What is the carrying capacity for fish in the ocean? A meta analysis of population dynamics of north Atlantic cod. Can. J. Fish. Aquatic Sci., 58: 1454-1476.

Odum, B.E. - 1959. Fundamentals of ecology. Saunders, Philadelphia.

Pauly, D., V. Christensen, and C.J. Walters. - 2000. Ecopath, Ecosim and Ecospace as tools for evaluating ecosystem impact of fisheries. ICES J. Mar. Sci., 57: 697-706.

Paine, R.T. - 1966. Food web complexity and species diversity. Am. Nat., 100: 65-75.

Petersen, C.G.J. - 1892. Fiskenbiologiske forhold I Holboek Fjorf 1890-1891. Beat. Danske Biol. Sla. 1890-1891, 1: 121-182.

Pitcher, T.J. - 2001. Fishery managed to rebuild ecosystems? Reconstructing the past to salvage the future. Ecol. Applic., 11(2): 601-617.

Pranovi F., S. Raicevich, G. Franceschini, M.G. Farrace, O. Giovanardi. - 2000. "Rapido" trawling in the Northern Adriatic Sea: effects on benthic communities in an experimental area. ICES J. Mar. Sci., 57: 517-524.

Ricker, W.E. - 1954. Stock and recruitment. J. Fish. Res. Bd. Can., 15: $991-1006$

Safran, P. - 1992. Theoretical analysis of the weight length relationship in fish juveniles. Mar. Biol., 112: 545-551.

Sánchez, P., M. Demestre, M. Ramón, M.J. Kaiser. - 2000. The impact of otter trawling on mud communities in the northwestern Mediterranean. ICES J. Mar. Sci., 57: 1352-1358.

Sánchez, P., F. Maynou and M. Demestre. - 2004. Modelling catcheffort and price in a juvenile Eledone cirrhosa fishery over a 10 year period. Fish. Res., 68: 319-328.

Sander, L.M. - 1986. Fractal growth processes. Nature, 322: 789-793.

Sardà, F., B. Molí and I. Palomera. - 2004. Preservation of juvenile 
hake (Merluccius merluccius, L.) in the western Mediterranean demersal trawl fishery by using sorting grids. Sci. Mar. 68(3): 435-444.

Schaefer, M.B. - 1957. A study of the dynamics of the fishery for yellowfin tuna in the eastern Pacific Ocean. Inter. Am. Trop. Tuna Comm. Bull., 2 :247-285.

Sell, J.R, Hopt-Landau. - 1984. Bifurcate near strange attractors. In: H. Haken (ed.), Chaos and order in nature, pp. 84-91. Springer Verlag, Berlin.

Shepherd, J.G. - 1982. A versatyle new stock-recruitment relationship for fisheries and the construction of sustainable yield curves. ICES. J. Mar. Sci.K, 40(1): 67-75.

Sinclair, A.R.E. - 1998. Predicting effects of predation on conservation of endangered prey. Conservation Biol., 12 : 564-575.

Solari, A.P., J.M. Martín González and C. Bas. - 1997. Stock and recruitment in Baltic cod (Gadus morhua): a new non-linear approach. ICES J. Mar. Sci., 54: 427-443.

Solari, A.P., J.J. Castro and C. Bas. - 2003. Skipjack tuna dynamics : similarities at several scales. In: L. Seuront and P.G. Strutton (eds.), Handbook of scaling methods in aquatic ecology. Measurement, Analysis, Simulation, pp.183-200. CRC Press, New York.
Solé, R.V. and S.C. Manrubia. - 1996. Orden y caos en los sistemas complejos. Universitat Politècnica de Catalunya, Barcelona.

Stokes, T. K. and R. Law. - 2000. Fishing as an evolutionary force. Mar. Ecol. Prog. Ser., 208: 307-309.

Trillas, E. - 1980. Conjuntos borrosos. Universitat Politècnica de Catalunya, Barcelona.

Verhulst, R.J. - 1838. Notice sur la loi que la population suit dans son accroissement. Correspondence mathematique et physique. 10: $113-121$

Volterra, V. - 1926. Fluctuations in the abundance of a species considered mathematically. Nature, 118: 558-560.

Walters, C. -2000 . Natural selection for predator avoidance tactics: implications for marine population and comunity dynamics. Mar. Ecol. Prog. Ser., 208: 309-313.

Walters, C., V. Christiansen and D. Pauly. - 1997. Structuring dynamic models of exploited ecosystems from trophic massbalance assessment. Rev. Fish Biol. Fish., 7:139-172.

Wilson, W., W.G Wilson and P. Lundberg. - 2004. Biodiversity and the Lotka-Volterra theory of species interactions: open systems and the distribution of logarithmic densities. Proc. Roy. Soc. London B, 271: 1977-1984. 